\title{
Relationship between Sex Hormone Binding Globulin, Thyroid Stimulating Hormone, Prolactin and Serum Androgens with Metabolic Syndrome Parameters in Iranian Women of Reproductive Age
}

\author{
Azita Zadeh-Vakili', Fahimeh Ramezani Tehrani ${ }^{2 *}$, Somayeh Hashemi ${ }^{2}$, Atieh Amouzegar ${ }^{3}$ and Fereidoun Azizi
}

Obesity Research Center, Research Institute for Endocrine Sciences, Shahid Beheshti University of Medical Sciences, Iran

Reproductive Endocrinology Research Center, Research Institute for Endocrine Sciences, Shahid Beheshti University of Medical Sciences, Iran

${ }^{3}$ Endocrine Research Center, Research Institute for endocrine sciences, Shahid Beheshti University of Medical Sciences, Tehran, Iran

\begin{abstract}
Background: In spite of increasing evidence that hormonal change might play a relevant role in the development of metabolic syndrome (MetS) in women, results are still controversial. Most studies examining this relationship have focused on women who carry an altered hormonal milieu. In this study we aimed at examining the association between androgens, prolactin, Thyroid Stimulating Hormone (TSH) and Sex Hormone Binding Globulin (SHBG) and MetS parameters in non-hyperandrogenic eumenorrheic reproductive aged women.
\end{abstract}

Methods: Subjects were 1126 women, 18-45 years old, selected randomly (using the stratified, multistage probability cluster sampling method) from among reproductive aged women of different geographic regions of Iran. Serum levels of hormones were measured and after implementation of exclusion criteria, complete data for 423 eumenorrheic non hirsute women remained for analysis.

Results: Androstendion (A4) was positively correlated with HDL-C $(p<0.01)$ while this correlation was negative in case of TSH $(p<0.005)$. A positive correlation was also detected between TSH and triglycerides $(p<0.01)$ while SHBG, prolactin and A4 were found to be negatively correlated with waist circumference (WC) $(p<0.02, p<0.001$ and $p<0.001$ respectively). In logistic regression analyses, after adjustment for age and body mass index, SHBG and prolactin remained associated with WC $(p<0.04, p<0.01$, respectively). The association between A4 and HDL-C was weakened but still marginally significant $(p=0.05)$.

Conclusions: These hormonal derangements suggest the involvement of metabolic risk factors and necessitate identification of high risk individuals, to facilitate treatment in order to improve their clinical status and prevent long term complications

Keywords: Metabolic syndrome; Sex hormone binding globulin; Iran; Prolactin

\section{Introduction}

Cardiovascular disease (CVD) has emerged as a major health problem worldwide. Based on current World Heart Federation guidelines[http://www.world-heart-federatio.org], the major CVD risk factors are obesity, hypertension, poor lipid profile parameters, and diabetes [1]. In the recent decades, many studies have been conducted to evaluate the relationship between hormones and cardiovascular risk factors [1-3,]. Prolactin has been reported as a potent lipogenic and diabetogenic factor [4,5], that affecting energy balance and fuel metabolism [6]. A study in postmenopausal women showed an association between BMI, an indicator of abdominal fat, and serum prolactin levels [7]. Steroid sex hormones also exert effects on CVD risk factors through their specific receptors which are widely expressed in several tissues including adipose tissue [8]. In women, whether present endogenously or administered exogenously, levels of estrogenic hormones are known to be correlated to increasing HDL levels, resulting in protection against CVD risk [9]. In terms of testosterone, most studies report an increased risk of CVD in women, due to androgenicity, characterized by high testosterone and low SHBG (Sex hormone binding globulin) levels [10-12]; however data from recent observational studies mostly show an inverse relationship between testosterone and CVD risk [13]. There are also many reports of the strong relation between central obesity in women and serum androgen levels [14-16]. The greater incidence of hypertension in postmenopausal women compared with premenopausal women suggests vascular effects of sex hormones that may contribute to the development of hypertension [17].

The majority of the above mentioned results are from studies on postmenopausal, obese or women with polycystic ovary syndrome, who carry an altered hormonal milieu. In the present study we aimed to investigate the relationship between metabolic syndrome parameters, as a risk factor for development of CVD, and hormones in women with no signs or symptoms of hyperandrogenemia (nonhirsute, normoovulatory) and also to assess the effect of extreme limits of normal measures on MetS parameters.

*Corresponding author: Fahimeh Ramezani Tehrani, Reproductive Endocrinology Research Center, Research Institute for Endocrine Sciences, Shahid Behesht University of Medical Sciences, PO Box 19395-4763, Tehran- Iran, Tel: +98/21/22409309; Fax: +98/21/22402463; E-mail: ramezani@endocrine.ac.ir

Received December 04, 2011; Accepted March 07, 2012; Published March 07 2012

Citation: Zadeh-Vakili A, Tehrani FR, Hashemi S, Amouzegar A, Azizi F (2012) Relationship between Sex Hormone Binding Globulin, Thyroid Stimulating Hormone, Prolactin and Serum Androgens with Metabolic Syndrome Parameters in Iranian Women of Reproductive Age. J Diabetes Metab S2:008. doi:10.4172/2155 6156.S2-008

Copyright: (C) 2012 Zadeh-Vakili A, et al. This is an open-access article distributed under the terms of the Creative Commons Attribution License, which permits unrestricted use, distribution, and reproduction in any medium, provided the original author and source are credited. 
Citation: Zadeh-Vakili A, Tehrani FR, Hashemi S, Amouzegar A, Azizi F (2012) Relationship between Sex Hormone Binding Globulin, Thyroid Stimulating Hormone, Prolactin and Serum Androgens with Metabolic Syndrome Parameters in Iranian Women of Reproductive Age. J Diabetes Metab S2:008. doi:10.4172/2155-6156.S2-008

Page 2 of 5

\section{Materials and Methods}

\section{Subjects}

The subjects of this study was selected from the Iranian PCOS Prevalence Study, a population based cross-sectional study of 1126 women, aged 18-45 years, was undertaken in 2009-2010 [18]. The eligible women were invited for a comprehensive interview and blood pressure, anthropometric, hormonal, and metabolic measurements. These data were completed for all except for 97 women who did not come to the clinics and 19 participants whose hormonal and metabolic profiles were not available. We also excluded women with PCOS using Rotterdam definition $(n=136)$, an ovulation $(n=77)$, polycystic ovaries $(n=74)$, hirsutism $(n=205)$, hypothyroid $(n=10)$ and women with hyperprolactinemia $(n=5)$. Furthermore those women who were pregnant at the time of study $(n=43)$, menopausal women $(n=37)$ were also excluded from the present study. For the purpose of the present study, all women aged 18-45 who don't meet our exclusion criteria were included. Finally 423 eumenorrheic non hirsute women were enrolled for the study.

All participants underwent clinical examinations, where body weight, height, waist and hip circumferences and blood pressure were measured by trained staff. Height and weight were measured with subjects in light clothes and without shoes, using standard apparatus. Weight was measured to the nearest $0.1 \mathrm{~kg}$ on a calibrated beam scale. Height and waist circumference (WC) were measured to the nearest 0.5 $\mathrm{cm}$ with a measuring tape. Waist was measured midway between the lower rib margin and the iliac-crest, at the end of a gentle expiration. Body mass index was calculated as weight in kilograms divided by the height in meters squared $\left(\mathrm{kg} / \mathrm{m}^{2}\right)$.

A blood sample for biochemical measurements was taken from each subject on the second or third day of their menstrual cycles, after 12 hours overnight fasting. Blood samples were collected in EDTAtreated test tubes. Informed consent was obtained from all participants before study entry.

\section{Laboratory measurements}

Plasma was separated in a refrigerated centrifuge at $3000 \mathrm{rpm}$ for ten minutes and sera were stored at $-80^{\circ} \mathrm{C}$ until tested. Fasting Blood Sugar (FBS) was measured using an enzymatic colorimetric method with Glucose Oxidase. Lipid measurements including Total Cholesterol (TC), Triglycerides (TG) and High Density Lipoprotein Cholesterol (HDL-C) were used by commercial assay kits (Pars Azmoon Inc., Tehran, Iran). TC and TG were assayed using enzymatic colorimetric tests with cholesterol esterase and cholesterol oxidase, and glycerol phosphate oxidase, respectively. HDL-C was measured after precipitation of the apolipoprotein B containing lipoproteins with phosphotungstic acid. All samples were analyzed when internal quality control met the acceptable criteria. In all biochemical analyses, the intra- and inter-assay coefficients of variation (CV) were less than $2.5 \%$ and $3.2 \%$ respectively. Androstendion (A4) was measured by enzyme immunoassay (EIA), (Diagnostic Biochem Canada Co. Ontario,Canada), and Sex Hormone Binding Globulin (SHBG) was measured by Immunoenzymometric assay (IEMA), (Mercodia, Uppsala, Sweden). All ELISA tests were performed using the Sunrise ELISA reader (Tecan Co. Salzburg, Austria). Prolactin (PRL), and Thyroid stimulating hormone (TSH) was measured by immunora diametric assay (IRMA), (Izotop, Budapest, Hungary) using gamma counter Wallac Wizard, Turku, Finland). The intra- and inter-assay coefficients of variation were: DHEAS: $2.0 \%$ and $5.1 \%$; SHBG: $1.2 \%$ and 5.7\%; A4: $2.2 \%$ and $3.5 \%$; TSH: $1.7 \%, 3.4 \%$, and PRL: $2.1 \%$ and $4.1 \%$.

\section{Definition}

Metabolic syndrome, based on the joint interim statement (JIS) definition, was considered to be the presence of any 3 of 5 risk factors of the following [19]: WC $\geq 95$ (country-specific cutoff point for Iranians [20]), HDL $<50, \mathrm{SBP} \geq 130$ or $\mathrm{DBP} \geq 85, \mathrm{TG} \geq 150$ and $\mathrm{FBS} \geq 100$.

\section{Statistical analysis}

Statistical analysis: Continuous variables were checked for normality using the one-sample Kolmogorov-Smirnoff test, and expressed as mean \pm standard deviation and/ or median (IQ 2575), as appropriate. Correlation between hormones concentrations and metabolic parameters were checked using the Pearson and the Spearman correlation coefficients for normal and non-normal values respectively. Logistic regression was used to identify the association between each MS component and hormonal parameters, after adjustment for other variables.

The hormonal concentrations were categorized to 4 quartiles, following which the mean or median of metabolic parameters were compared between 1st and 4th quartiles using the $\mathrm{T}$ and MannWhitney tests for normal and non-normal values respectively.

\section{Results}

Clinical and metabolic characteristics of the women participants are presented in Table 1. Table 2 shows the correlation coefficients

\begin{tabular}{lc}
\hline Variable & $\begin{array}{l}\text { Value } \\
\text { (Means } \pm \mathrm{SD})\end{array}$ \\
\hline Age $($ Years $)$ & $35.3 \pm 7.4$ \\
Systolic blood pressure $(\mathrm{mmHg})$ & $109.01 \pm 13.7$ \\
Diastolic blood pressure $(\mathrm{mmHg})$ & $68.8 \pm 10.9$ \\
Total cholesterol $(\mathrm{mg} / \mathrm{dl})$ & $185.7 \pm 43.2$ \\
LDL cholesterol $(\mathrm{mg} / \mathrm{dl})$ & $112.6 \pm 37.3$ \\
HDL cholesterol $(\mathrm{mg} / \mathrm{dl})$ & $44.6 \pm 13$ \\
Triglycerides $(\mathrm{mg} / \mathrm{dl})$ & $142.09 \pm 96.4$ \\
Weight $(\mathrm{kg})$ & $66.7 \pm 12.3$ \\
Height $(\mathrm{m})$ & $158.2 \pm 6.1$ \\
BMI $\left(\mathrm{kg} / \mathrm{m}^{2}\right)$ & $26.7 \pm 5.02$ \\
Waist $(\mathrm{cm})$ & $84.6 \pm 11.9$ \\
Hip $(\mathrm{cm})$ & $104.8 \pm 11.1$ \\
Fasting blood sugar $(\mathrm{mg} / \mathrm{dl})$ & $88.4 \pm 21.3$ \\
Prolactin $(\mu \mathrm{gg} / \mathrm{ml})$ & $16.05 \pm 10.4$ \\
SHBG $(\mathrm{nmol} / \mathrm{l})$ & $72.6 \pm 24.1$ \\
Testosterone $(\mathrm{nmol} / \mathrm{l})$ & $0.5 \pm 0.2$ \\
A4 $(\mathrm{ng} / \mathrm{ml})$ & $1.29 \pm 0.49$ \\
\hline
\end{tabular}

BMI: Body Mass Index; SHBG: Sex Hormone Binding Globulin; A4: Androstendion

Table 1: Clinical and metabolic characteristics of the study subjects $(n=423)$.

\begin{tabular}{|c|c|cccccc|}
\hline & & HDL-C & TG & SBP & DBP & FBS & WC \\
\hline \multirow{2}{*}{ Prolactin $(\mu \mathrm{g} / \mathrm{ml})$} & $\mathrm{r}$ & 0.1 & -0.04 & -0.03 & -0.01 & -0.01 & -0.16 \\
& $\mathrm{P}$ & 0.02 & 0.37 & 0.5 & 0.8 & 0.7 & 0.001 \\
\hline \multirow{2}{*}{ SHBG $(\mathrm{nmol} / \mathrm{l})$} & $\mathrm{r}$ & 0.06 & -0.09 & -0.01 & -0.005 & 0.12 & -0.11 \\
& $\mathrm{P}$ & 0.18 & 0.05 & 0.8 & 0.9 & 0.01 & 0.02 \\
\hline \multirow{2}{*}{ Testosterone $(\mathrm{nmol} / \mathrm{l})$} & $\mathrm{r}$ & 0.04 & -0.08 & 0.02 & -0.05 & -0.02 & -0.08 \\
& $\mathrm{P}$ & 0.41 & 0.07 & 0.04 & 0.3 & 0.5 & 0.07 \\
\hline \multirow{2}{*}{ A4(ng/ml) } & $\mathrm{r}$ & 0.12 & -0.07 & -0.04 & -0.08 & -0.05 & -0.19 \\
& $\mathrm{P}$ & 0.01 & 0.13 & 0.36 & 0.07 & 0.3 & 0.00 \\
\multirow{2}{*}{$\mathrm{TSH}(\mathrm{mIU} / \mathrm{l})$} & $\mathrm{r}$ & -0.13 & 0.12 & 0.08 & 0.14 & 0.1 & 0.09 \\
& $\mathrm{P}$ & 0.005 & 0.01 & 0.09 & 0.02 & 0.05 & 0.07 \\
\hline
\end{tabular}

Table 2: Correlation coefficients $(r)$ serum hormone concentrations with metabolic syndrome parameters. 
Citation: Zadeh-Vakili A, Tehrani FR, Hashemi S, Amouzegar A, Azizi F (2012) Relationship between Sex Hormone Binding Globulin, Thyroid Stimulating Hormone, Prolactin and Serum Androgens with Metabolic Syndrome Parameters in Iranian Women of Reproductive Age. J Diabetes Metab S2:008. doi:10.4172/2155-6156.S2-008

Page 3 of 5

of the serum hormones concentrations and metabolic syndrome parameters. All of the measured hormones except testosterone and TSH were correlated with WC. In addition, A4 was significantly correlated with HDL-C and DBP. Also TSH was correlated with SBP. Our results have shown that FBS was significantly correlated with TSH and SHBG concentrations. Clinical and metabolic characteristics of subjects are presented in table 1 .

Logistic regression analyses were performed to investigate the association between serum hormones concentration with metabolic syndrome risk factors after adjustment for age and BMI (Table 3). Inverse associations between SHBG and prolactin with WC were revealed. A significant positive association was seen between SHBG and A4 with FBS and HDL respectively. We also found an association between TSH concentration and TG.

Serum hormones concentrations were classified into four groups and MS parameters were compared in lower and higher quartiles. Our analyses revealed that DBP, HDL, FBS and WC are significantly different between quartiles 1 and 4 of TSH concentration. Also, FBS and WC differed in the two groups of SHBG concentration values (Figure 1).
Our results have also shown that the prevalence of MS in subjects with lower PRL are significantly greater than those with higher PRL, however prevalence of MS in groups with high and low TSH, A4 and SHBG were not significantly different.

There were 54 women who use oral contraceptive pill, excluding those women from data was not changed the results.

\section{Discussion}

The results of our study provide evidence showing the correlation between serum hormones concentration and parameters of metabolic syndrome. An association was found between serum TSH, prolactin, and SHBG and waist circumferences, data which suggest that extreme limits of these hormones are accompanied with higher cardio metabolic risks.

Central obesity is associated with reduced serum SHBG and in our study this association remained significant even after adjustment for age and BMI. Reinecke et al. [21] showed that hyperandrogenemia and low sex hormone binding globulin (SHBG) are frequently found in patients with metabolic syndrome. The results of our study is also concordant with those of a recent systematic review by Brand et al. [22]

\begin{tabular}{|c|c|c|c|c|c|c|c|c|c|c|c|c|}
\hline & \multicolumn{2}{|c|}{ SHBG } & \multicolumn{2}{|c|}{ A4 } & \multicolumn{2}{|l|}{ prolactin } & \multicolumn{2}{|l|}{ TSH } & \multicolumn{2}{|l|}{ BMI } & \multicolumn{2}{|l|}{ age } \\
\hline & $\mathrm{B}(\mathrm{SE})$ & $\mathrm{P}$ & $\mathrm{B}(\mathrm{SE})$ & $P$ & $\mathrm{~B}(\mathrm{SE})$ & $\mathrm{P}$ & $\mathrm{B}(\mathrm{SE})$ & $P$ & $\mathrm{~B}(\mathrm{SE})$ & $P$ & $\mathrm{~B}(\mathrm{SE})$ & $\mathrm{P}$ \\
\hline HDL-C & $0.004(0.005)$ & 0.3 & $0.4(0.2)$ & 0.05 & $-0.002(0.01)$ & 0.8 & $-0.1(0.04)$ & 0.1 & $-0.1(0.02)$ & 0 & $0.01(0.01)$ & 0.3 \\
\hline TG & $0.005(0.005)$ & 0.2 & $0.1(0.2)$ & 0.6 & $0.008(0.01)$ & 0.4 & $-0.08(0.03)$ & 0.02 & $-0.09(0.02)$ & 0 & $-0.01(0.01)$ & 0.2 \\
\hline HBP & $0.006(0.007)$ & 0.4 & $-0.1(0.3)$ & 0.7 & $-0.01(0.01)$ & 0.6 & $0.06(0.04)$ & 0.1 & $0.09(0.03)$ & 0.004 & $0.1(0.03)$ & 0.001 \\
\hline FBS & $0.01(0.006)$ & 0.01 & $-0.1(0.3)$ & 0.7 & $-0.02(0.01)$ & 0.2 & $0.04(0.04)$ & 0.3 & $0.1(0.03)$ & 0 & $0.03(0.02)$ & 0.1 \\
\hline WC & $-0.01(0.06)$ & 0.04 & $-0.3(0.2)$ & 0.1 & $-0.04(0.01)$ & 0.01 & $0.02(0.03)$ & 0.5 & & & $0.07(0.02)$ & 0 \\
\hline
\end{tabular}

Table 3: Association between concentrations of serum hormones with metabolic syndrome risk factors.
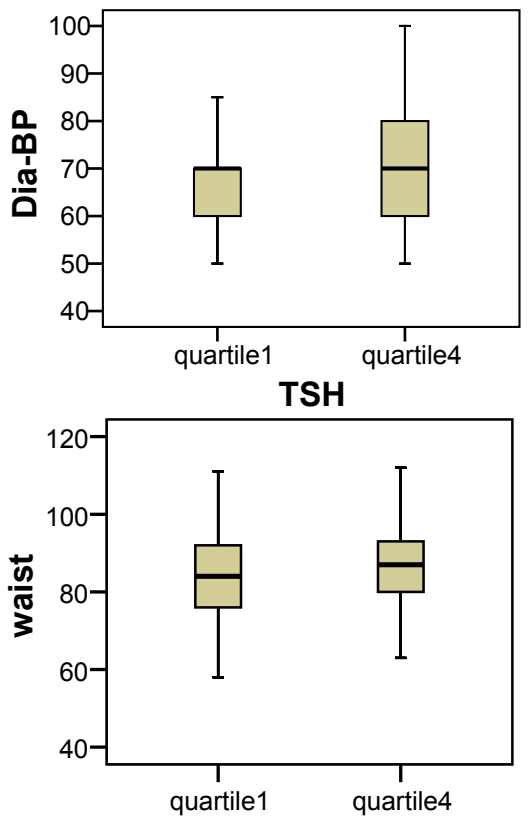

TSH
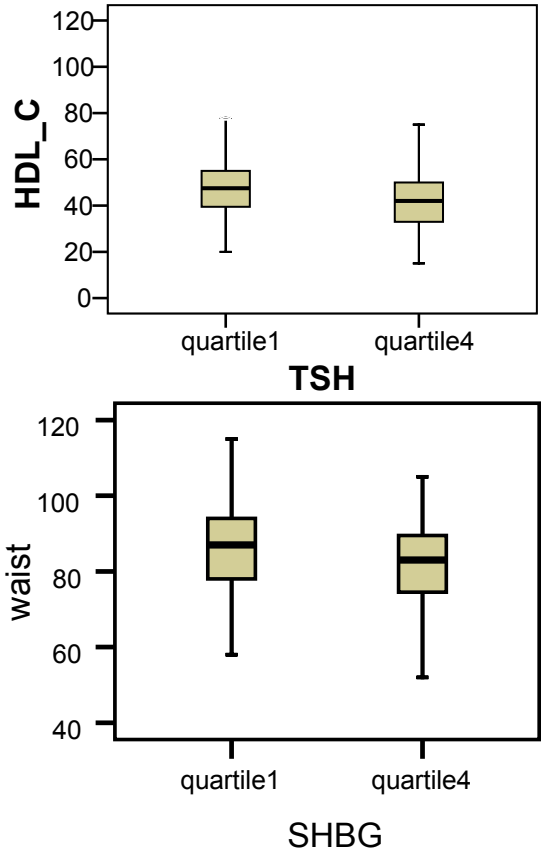
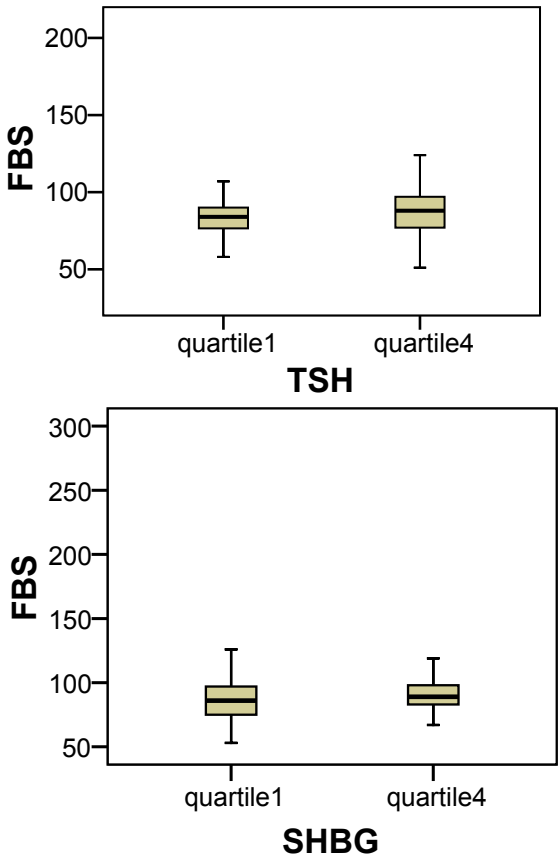

1. We did not present the $95 \% \mathrm{Cl}$ for the mean in figure 1 and we presented the percentiles of $5,25,50,75$ and 95 . Therefore it seems that their overlaps has no effect on the interpretation of our results

Figure 1: Association of MetS parameters with lower and higher quartile of TSH and SHBG concentration [1]. 
Citation: Zadeh-Vakili A, Tehrani FR, Hashemi S, Amouzegar A, Azizi F (2012) Relationship between Sex Hormone Binding Globulin, Thyroid Stimulating Hormone, Prolactin and Serum Androgens with Metabolic Syndrome Parameters in Iranian Women of Reproductive Age. $J$ Diabetes Metab S2:008. doi:10.4172/2155-6156.S2-008

concluding that, in both men and women, MetS is associated with lower SHBG levels. In fact, serum hormones level influence the development of CVD both indirectly, by developing secondary metabolic changes such as increased WC, obesity, hypertension, insulin resistance, or dyslipidemia, and directly, by inducing significant changes in cellular pathways that promote the process of atherogenesis, and thrombosis.

Based on our results, there is an inverse association between serum prolactin, and waist circumferences. Although contrary to our findings Kok et al. showed enhanced secretion of prolactin in obese patients, they evaluated only 11 patients with morbid obesity and dose not coincide with the population of this study [5]. In contrast to our results, Ernst B et al., found neither any significant association between basal serum PRL levels and the degree of obesity or related metabolic disturbances nor any systematic changes in basal concentrations of the hormone after massive weight loss, they also showed that excess energy primarily toward the visceral fat depot is promoted directly by prolactin [23]. It should be noted that study of Ernst B et al. included a mixed population (men and women) with an age range involving postmenopausal women, therefore it is hoped that the results do not match.

Our data confirmed a significant difference on metabolic syndrome's components such as low HDL-cholesterol and waist circumference between women whose serum TSH level is in $1^{\text {st }}$ quartile in comparison to those in $4^{\text {th }}$ quartile (Figure 1). Ruhla $S$ et al. [24] also confirmed significant positive correlations between TSH in euthyroid subjects and obesity, high triglycerides, and an increased likeliness for the metabolic syndrome, suggesting therefore that TSH level below $2.5 \mathrm{mU} / \mathrm{l}$ are associated with a favorable metabolic profile. Recent investigation in Korean population [25] showed that higher levels of TSH may predict the MetS. Thyroid hormones have many effects on metabolic changes in the body, through stimulating basal metabolic rate.

Our findings showed a favorable association between FBS with TSH and SHBG concentration that remained after adjustment for age and BMI. Park SB et al. [25] also found higher levels of TSH to be associated with increased insulin resistance, even after adjustment for the confounding factors. Carbohydrate metabolism, both in skeletal muscle and adipose tissue seems to be affected by thyroid hormones through the action of insulin. The results of our study indicates that insulin probably plays active roles for modulation of serum SHBG levels and increasing insulin level suppresses SHBG production [26]; this is more enhanced in patients with obesity, and a reduced level of SHBG may be an indication of an hyper androgenic state, and a marker for prediction of insulin resistance. Suppressed level of SHBG accompanied by high serum androgen level may be a marker for endocrine and metabolic risk factors.

One of the strengths of our study was that the analyses based on a large cross-sectional community based sample. Further we were able to investigate a broad range of anthropometric parameters and hormone levels and able to determine the independent association between endogenous hormones and metabolic parameters in multivariate analyses. Certain limitations should be kept in mind in interpreting our data. The cross-sectional design of the present study allows no conclusion regarding causality and a prospective cohort study is suggested to investigate the causality direction. Our study was conducted among a narrow age range (reproductive period) therefore our results are not be generalizable to other age or sex subjects.

Our data suggests that extreme limits of hormonal levels could be associated with metabolic syndrome components and cardiovascular risk. The results of the present study may be useful for better understanding of the path physiology of metabolic syndrome

\section{Acknowledgements}

We are indebted to each of the study participants for the substantial time and effort contributed to this study. Acknowledgments are also due to the research staff at the health department of Ghazvin, Golestan, Kermanshah and Hormozgan provinces. Our special thanks to Dr. M. Tohidi for her important contribution on testing and to Ms. N. Shiva for language editing of the manuscript. The authors also thank the National Council of Scientific Research of the I.R. Iran for the approval and finding of this national research project.

\section{References}

1. Muller M, van der Schouw YT, Thijssen JHH, Grobbee DE (2003) Endogenous Sex Hormones and Cardiovascular Disease in Men. J Clin Endocrinol Metab 88: $5076-5086$

2. Friedrich N, Rosskopf D, Brabant G, Volzke H, Nauck M, et al. (2010) Associations of anthropometric parameters with serum TSH, prolactin, IGF-I, and testosterone levels: results of the study of health in Pomerania (SHIP). Exp Clin Endocrinol Diabetes 118: 266-273.

3. Kumagai S, Kai Y, Sasaki H (2001) Relationship between insulin resistance, sex hormones and sex hormone-binding globulin in the serum lipid and lipoprotein profiles of Japanese postmenopausal women. J Atheroscler Thromb 8: 14-20.

4. Bole-Feysot C, Goffin V, Edery M, Binart N, Kelly PA (1998) Prolactin (PRL) and its receptor: actions, signal transduction pathways and phenotypes observed in PRL receptor knockout mice. Endocr Rev 19: 225-268.

5. Kok P, Roelfsema F, Langendonk JG, de Wit CC, Frolich M, et al. (2006) Increased circadian prolactin release is blunted after body weight loss in obese premenopausal women. Am J Physiol Endocrinol Metab 290: E218-224.

6. Kok P, Roelfsema F, Frolich M, Meinders AE, Pijl H (2004) Prolactin release is enhanced in proportion to excess visceral fat in obese women. J Clin Endocrino Metab 89: 4445-4449.

7. McTiernan A, Wu L, Chen C, Chlebowski R, Mossavar-Rahmani Y, et al. (2006) Relation of BMI and physical activity to sex hormones in postmenopausa women. Obesity (Silver Spring) 14: 1662-1677.

8. Rodriguez-Cuenca S, Monjo M, Proenza AM, Roca P (2005) Depot differences in steroid receptor expression in adipose tissue: possible role of the local steroid milieu. Am J Physiol Endocrinol Metab 288: E200-E207.

9. Dobs AS, Bachorik PS, Arver S, Meikle AW, Sanders SW, et al. (2001) Interrelationships among lipoprotein levels, sex hormones, anthropometric parameters, and age in hypogonadal men treated for 1 year with a permeationenhanced testosterone transdermal system. J Clin Endocrinol Metab 86: 10261033.

10. Brand JS, van der Schouw YT (2010) Testosterone, SHBG and cardiovascula health in postmenopausal women. Int J Impot Res 22: 91-104.

11. Guthrie JR, Dennerstein L, Taffe JR, Ebeling PR, Randolph JF, et al. (2003) Central abdominal fat and endogenous hormones during the menopausal transition. Fertil Steril 79: 1335-1340.

12. Janssen I, Powell LH, Kazlauskaite R, Dugan SA (2009) Testosterone and Visceral Fat in Midlife Women: The Study of Women's Health Across the Nation (SWAN) Fat Patterning Study. Obesity 18: 604-610.

13. Davis SR (2011) Cardiovascular and cancer safety of testosterone in women. Curr Opin Endocrinol Diabetes Obes 18: 198-203.

14. Patel SM, Ratcliffe SJ, Reilly MP, Weinstein R, Bhasin S, et al. (2009) Higher serum testosterone concentration in older women is associated with insulin resistance, metabolic syndrome, and cardiovascular disease. J Clin Endocrino Metab 94: 4776-4784.

15. Schmidt J, Brannstrom M, Landin-Wilhelmsen K, Dahlgren E (2011) Reproductive Hormone Levels and Anthropometry in Postmenopausal Women with Polycystic Ovary Syndrome (PCOS): A 21-Year Follow-Up Study of Women Diagnosed with PCOS around 50 Years Ago and Their Age-Matched Controls. J Clin Endocrinol Metab 96: 2178-2185.

16. Soteriades ES, Hauser R, Kawachi I, Liarokapis D, Christiani DC, et al. (2005) Obesity and Cardiovascular Disease Risk Factors in Firefighters: A Prospective Cohort Study. Obes Res 13: 1756-1763. 
Citation: Zadeh-Vakili A, Tehrani FR, Hashemi S, Amouzegar A, Azizi F (2012) Relationship between Sex Hormone Binding Globulin, Thyroid Stimulating Hormone, Prolactin and Serum Androgens with Metabolic Syndrome Parameters in Iranian Women of Reproductive Age. J Diabetes Metab S2:008. doi:10.4172/2155-6156.S2-008

Page 5 of 5

17. Khalil RA (2005) Sex hormones as potential modulators of vascular function in hypertension. Hypertension 46: 249-254.

18. Tehrani FR, Simbar M, Tohidi M, Hosseinpanah F, Azizi F (2011) The prevalence of polycystic ovary syndrome in a community sample of Iranian population: Iranian PCOS prevalence study. Reprod Biol Endocrinol 9: 39.

19. Alberti KG, Eckel RH, Grundy SM, Zimmet PZ, Cleeman JI, et al. (2009) Harmonizing the metabolic syndrome: a joint interim statement of the International Diabetes Federation Task Force on Epidemiology and Prevention National Heart, Lung, and Blood Institute; American Heart Association; World Heart Federation; International Atherosclerosis Society; and International Association for the Study of Obesity. Circulation 120: 1640-1645.

20. Azizi F, Khalili D, Aghajani H, Esteghamati A, Hosseinpanah F, et al. (2010) Appropriate waist circumference cut-off points among Iranian adults: the first report of the Iranian National Committee of Obesity. Arch Iran Med 13: 243-244.

21. Reinecke H, Bogdanski J, Woltering A, Breithardt G, Assmann G, et al. (2002) Relation of serum levels of sex hormone binding globulin to coronary heart disease in postmenopausal women. Am J Cardiol 90: 364-368.
22. Brand JS, van der Tweel I, Grobbee DE, Emmelot-Vonk MH, van der Schouw YT (2011)Testosterone, sex hormone-binding globulin and the metabolic syndrome: a systematic review and meta-analysis of observational studies. Int J Epidemiol 40: 189-207.

23. Ernst B, Thurnheer M, Schultes B (2009) Basal serum prolactin levels in obesity--unrelated to parameters of the metabolic syndrome and unchanged after massive weight loss. Obes Surg 19: 1159-1162.

24. Ruhla S, Weickert MO, Arafat AM, Osterhoff M, Isken F, et al. (2010) A high normal TSH is associated with the metabolic syndrome. Clin Endocrinol (Oxf) 72: 696-701.

25. Park SB, Choi HC, Joo NS (2011) The relation of thyroid function to components of the metabolic syndrome in korean men and women. J Korean Med Sci 26 : 540-545.

26. Plymate SR, Matej LA, Jones RE, Friedl KE (1988) Inhibition of sex hormonebinding globulin production in the human hepatoma (Hep G2) cell line by insulin and prolactin. J Clin Endocrinol Metab 67: 460-464. 